\title{
La Evaluación Inicial o Diagnóstica en la Enseñanza Superior. Un ejemplo en la asignatura de Teoría e Historia del Arte
}

Manuel ANTONio Ramos SuÁrez

Universidad de Sevilla

Departamento de Escultura e

Historia de las Artes Plásticas.

mantonioramos@us.es

ORCID: https://orcid.org/0000-0001-8397-6532

D.O.I.: http://dx.doi.org/10.12795/JDU.2018.i01.34

Pp.: 600-618

\section{Resumen}

Con la presente comunicación se estudia, analiza y valora la importancia de la evaluación inicial o diagnóstica en la asignatura de Teoría e Historia del Arte del grado de Bellas Artes y Conservación y Restauración de Bienes Culturales de la Facultad de Bellas Artes de la Universidad de Sevilla. Tras valorar la capacidad del alumnado a la hora de enfrentarse a la nueva asignatura y descubrir cuáles son los métodos de aprendizaje, se van a emplear varias fórmulas para obtener un diagnóstico que permita evaluar los contenidos de cada uno de los temas expuestos en la asignatura y proceder a reprogramar la asignatura en función de las competencias y contenidos adquiridos. Dadas las características, este procedimiento podrá ser aplicado a otros ámbitos de la Enseñanza Superior. 
Palabras clave: Asignatura, titulación, docencia universitaria, Renovación docente universitaria, evaluación.

\section{Breve descripción del contexto de la intervención}

La intervención se ha realizado en la asignatura "Teoría e Historia del Arte II" de primer curso de los grados de Bellas Artes y de Conservación y Restauración en la Facultad de Bellas Artes de la Universidad de Sevilla en el segundo cuatrimestre. La asignatura se imparte los miércoles y viernes en horario de tarde. El número total de estudiantes era de cuarenta y un alumnos, veinticinco alumnas y dieciséis alumnos, aunque de forma habitual asisten a las sesiones unos veinticinco alumnos.

El espacio donde se realizó la actividad es en el Aula de Teoría 2 del Edificio Gonzalo Bilbao, anexo de la Facultad de Bellas Artes, sito en c/ Gonzalo Bilbao, 7-9 de Sevilla. La distribución espacial del aula no es la más adecuada para el diálogo (bancas ancladas al suelo y en dos grandes bloque que dejan un pasillo en su parte central y en uno de los laterales) Esta dificultad se salvó poniendo cada uno de su parte, y los propios alumnos adoptaban posturas para poder dialogar con el resto. El profesor no emplea la tarima para establecer un diálogo más cercano con los alumnos. De esa forma se fomenta una clase más dinámica y participativa y su distribución es menos impedimento.

\section{Mi modelo habitual y el posible ciclo de Mejora.}

Tras haber realizado Seminario de Iniciación sobre el análisis crítico y mejora de la práctica profesional durante el curso 2015-2016 y haber planteado y ejecutado un ciclo de mejora y propuestas metodológicas para la asignatura de Teoría e Historia del Arte II (Ramos 2016; 2017) este año en el transcurso del segundo cuatrimestre del curso 
2017-2018 y en la misma asignatura, me planteé iniciar una nueva propuesta metodológica que enriqueciera el modelo didáctico ya establecido en la materia, esta vez orientada a la evaluación inicial o diagnóstica.

Mi modelo habitual ya se expuso el pasado curso en las III Jornadas de Docencia Universitaria. (Ramos Suárez, 2016) En ellas se planteaba una clase magistral dando participación al alumnado en el desarrollo de la misma desde el comienzo haciendo un resumen de lo expuesto en la sesión anterior, haciéndole partícipe de su opinión a la hora de analizar aspectos principales o particulares de la obra de arte y también protagonista de su propio aprendizaje. Con este ciclo de mejora se pretende que el propio alumno/a vuelva a ser partícipe y protagonista de su propio aprendizaje. Para ello, y sin desechar ninguno de los elementos propuestos en el modelo didáctico habitual, se incluirá la evaluación inicial o diagnóstica desde la primera sesión de la asignatura pasándoles una encuesta hasta la valoración inicial a nivel de contenidos conceptuales, procedimentales y actitudinales de los temas expuestos.

Considerando la evaluación como un proceso continuo en el que se desarrollan tres acciones claves: recoger información, analizarla y valorarla y tomar decisiones coherentes (Giné y Parcerisa, 2000), hay que tener en cuenta que recoger información no corresponde solo a los estudiantes y su aprendizaje sino también al profesorado y sus proyectos docentes. Gracias a esa información recibida y su análisis se emiten juicios sobre el grado de aprendizaje y finalidades planteadas y se toman decisiones como la calificación, entre otras. (Rivero y Porlán, 2017)

Por tanto, entendiendo que la evaluación es un medio para mejorar los resultados de la actividad evaluada, la evaluación sirve para tener buena y verosímil información tanto del proceso como de los resultados. El uso de esa información servirá para tomar decisiones y poder cambiar aquello que haya que mejorar.

Una de las tareas a realizar dentro de la evaluación inicial es reconocer cómo cada uno de nuestros alumnos 
organiza la información recibida, y cuál es su estilo de aprendizaje. Para ello emplearemos el cuestionario Honey-Alonso donde los modelos se clasificarán en cuatro estilos de aprendizaje: Activo, Reflexivo, Teórico y Pragmático. (Honey, Gallego y Alonso, 1994) Tras su realización y haciéndoles ver que se trata de un cuestionario anónimo, que no se trata de un test de inteligencia y que no hay respuestas correcta ni erróneas, se podrán conocer cómo aprenden estos estudiantes.

Posteriormente se aplicarán distintas técnicas evaluadoras en cada uno de los temas presentados en el programa de la asignatura, valorando los resultados de forma colectiva y reformulando contenidos conceptuales, procedimentales y actitudinales, así como la futura metodología a emplear. En primer lugar, y para el tema 4 se realizará un torbellino de ideas, para abordar el tema 5 se practicará un cuestionario kahoot, ambos para dinamizar el aula y obtener algunas ideas previas sobre los temas a tratar. Finalmente, en el tema 6 y pretendiendo diagnosticar los modelos mentales del alumnado, se realizará un cuestionario sobre los contenidos de la materia. (Anexo II) Tras el análisis y estudio del cuestionario se replantearán los tipos de contenidos para su presentación en las clases.

El clima de trabajo en la asignatura es especialmente bueno. La motivación del alumnado es muy positiva. Y a pesar del horario que tiene la asignatura, como ya se ha expuesto, los alumnos/as con sus intervenciones y preguntas propician un clima de trabajo muy favorable. Al alumnado se le ha expuesto que van a formar parte de un programa de mejora con enfoques metodológicos distintos, están de acuerdo y son conscientes que los resultados van a revertirles personalmente en una nueva forma de recibir la docencia en la asignatura.

Aunque de todos es conocido que en las distintas etapas educativas de la educación no universitaria: Educación Infantil, Educación obligatoria -Primaria y Secundaria- e incluso en el Bachillerato y Ciclos Formativos, es de suma 
importancia la evaluación inicial o diagnóstica. Y si así se practica en cada uno de los niveles, no ocurre lo mismo en el ámbito de la Enseñanza Superior o Universitaria. Sin embargo, en los últimos años, son numerosos profesores los que ponen de manifiesto que esta evaluación es primordial para iniciar su camino en sus asignaturas.

Básicamente se plantean los contenidos que se pretende que cada alumno domine a la hora de trabajar los distintos temas del temario.

En primer lugar, entre los contenidos actitudinales que se valoran a la hora de realizar el primer cuestionario inicial (Anexo I) están: Saber si los alumnos proceden o no del Bachillerato Artístico y si han recibido docencia relacionada con la Historia del Arte, si se han examinado alguna vez y cuáles han sido los resultados en esa asignatura, si se presentaron a la materia de Historia del Arte en Selectividad y cuáles fueron los resultados y finalmente, si han recibido docencia en la facultad sobre Teoría e Historia del Arte I y II y cuáles han sido los resultados. Estas preguntas dentro del cuestionario inicial permitirán saber de forma general, de qué nivel parten los alumnos. También se podrán valorar contenidos procedimentales a la hora de hacer comentario de imágenes, procedimiento básico y primordial en esta asignatura. (Fig. 1) 


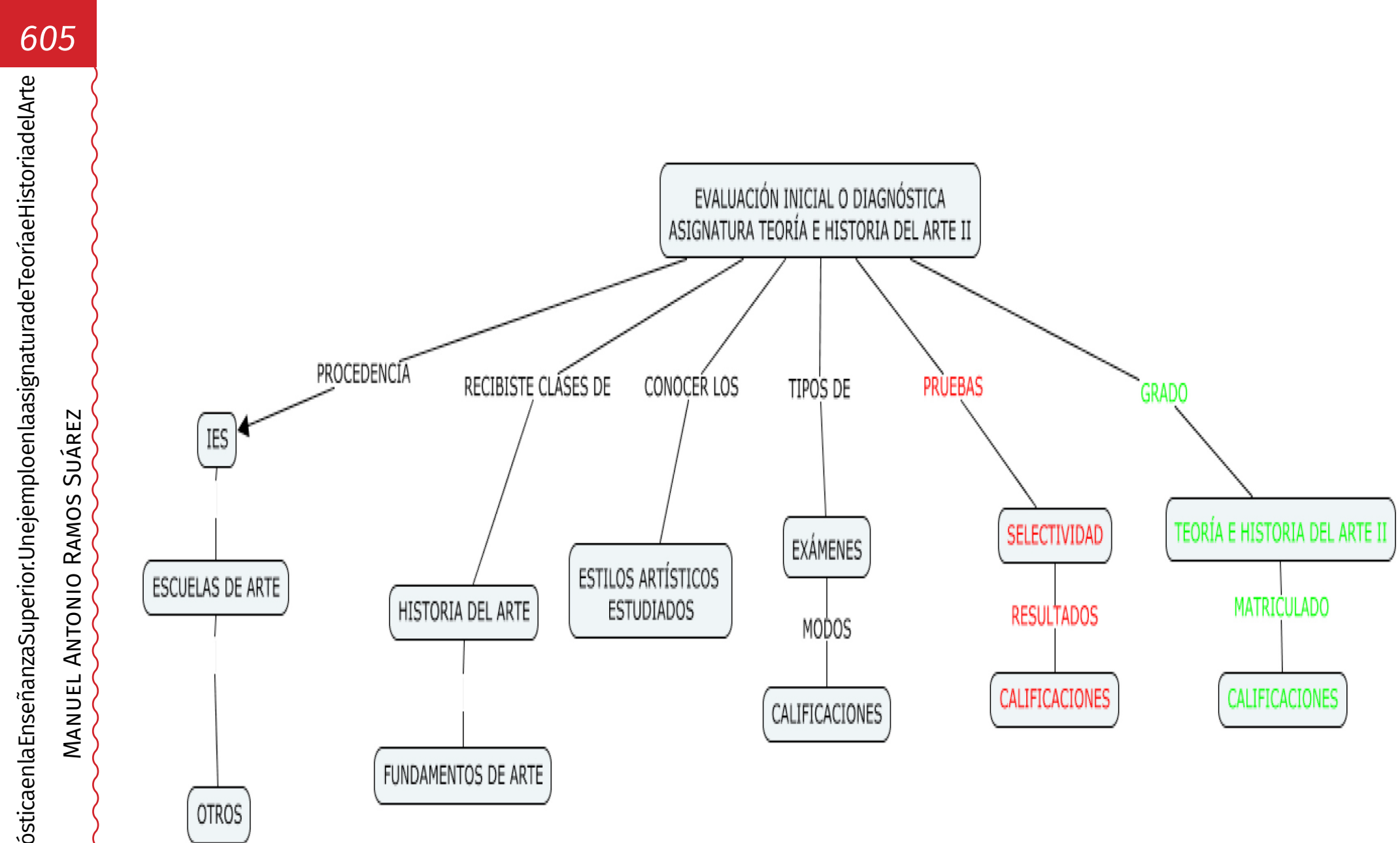

Fig. 1. Mapa conceptual para la Evaluación Inicial o diagnóstica de la asignatura

Jornadas de Formación e Innovación Docente del Profesorado | № 1 (2018)

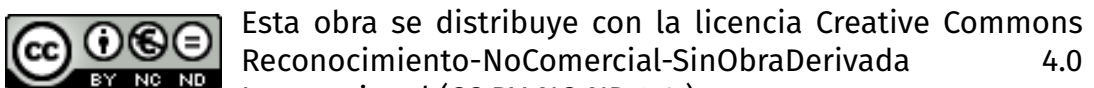

Internacional (CC BY-NC-ND 4.0.) 
En segundo lugar, se plantea la elaboración de un cuestionario Honey genérico con la intención de conocer el modelo de aprendizaje del alumnado de forma general, sobre todo, para conocer la forma en la que el alumnado aprende.

En tercer lugar, se analizan cada uno de los temas donde se aplicará el ciclo de mejoras. Para hacer una evaluación inicial del último tema se presentará un cuestionario previo de evaluación inicial por escrito y una vez valorado, se presentará el mapa de contenidos a tratar. (Fig 2)

El mapa de contenidos tras valorar este cuestionario es el siguiente: 


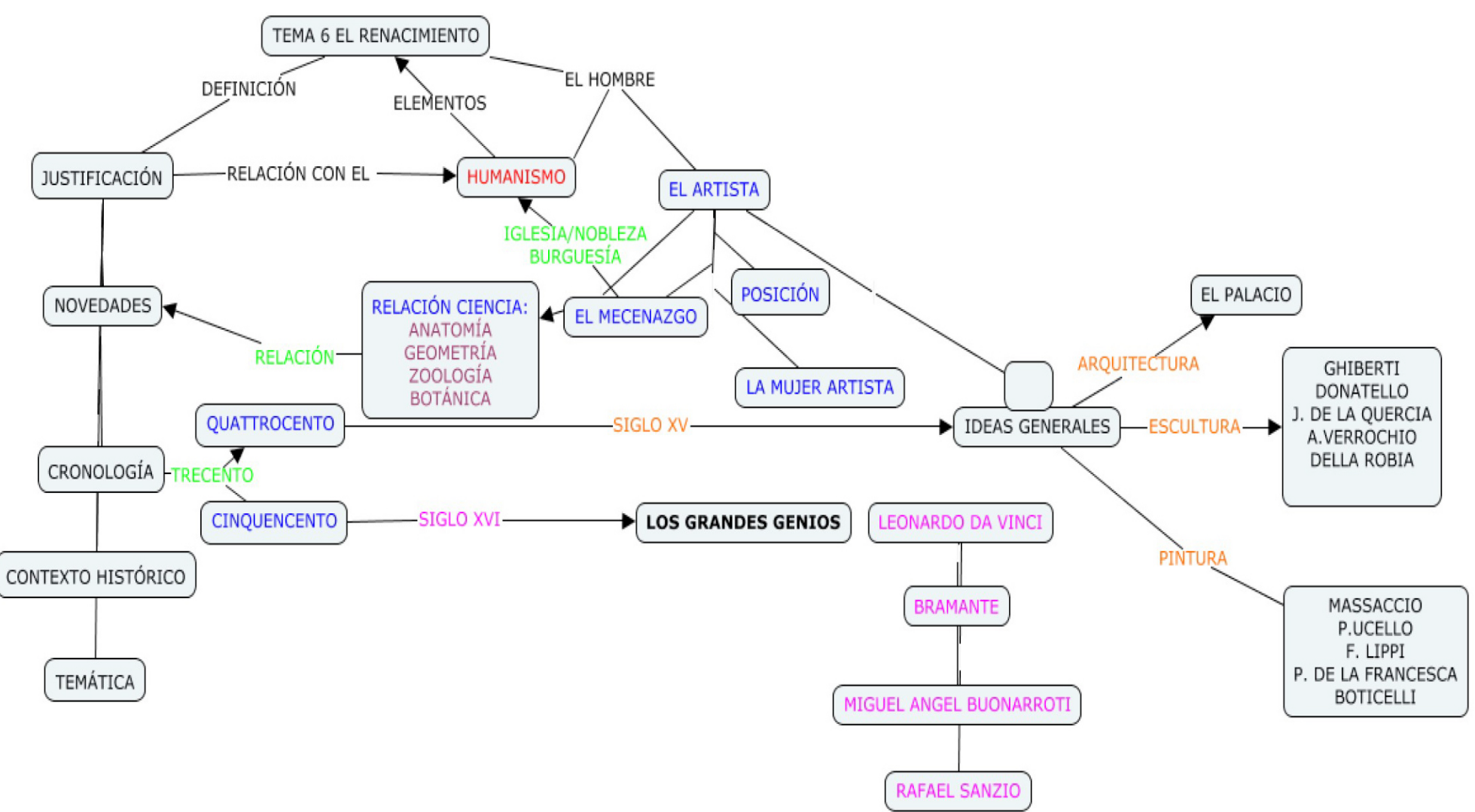

Fig. 2. Mapa conceptual. El Renacimiento

Jornadas de Formación e Innovación Docente del Profesorado | № 1 (2018)

(c) (i) $\odot$ Esta obra se distribuye con la licencia Creative Commons

Internacional (CC BY-NC-ND 4.0.) 
La secuencia de actividades viene recogida en este cuadro-esquema de la temporalización.

\begin{tabular}{|c|c|c|c|}
\hline TEMP & ACTIVIDADES & METODOLOGÍA & EVALUAC. \\
\hline $\begin{array}{l}\text { 1á } \\
\text { Sesión } \\
\text { Inicio de } \\
\text { la clase } \\
\text { (15min.) }\end{array}$ & $\begin{array}{l}\text { EVALUA- } \\
\text { CIÓN INICIAL O } \\
\text { DIAGNÓSTICA }\end{array}$ & $\begin{array}{l}\text { El profesor presenta este cues- } \\
\text { tionario inicial resuelto con va- } \\
\text { rios ítems resolviendo como llega } \\
\text { el alumnado a la Facultad de Be- } \\
\text { llas Artes y por consiguiente a la } \\
\text { Asignatura de Teoría e Historia del } \\
\text { Arte II. Cada alumno lo contesta de } \\
\text { forma anónima e individual. } \\
\text { Ver Anexo I. } \\
\text { Modelo Cuestionario Previo. }\end{array}$ & $\begin{array}{l}\text { Por parte del } \\
\text { Profesor. }\end{array}$ \\
\hline $\begin{array}{l}\text { 2a se- } \\
\text { sión. Ini- } \\
\text { cio de la } \\
\text { clase. } \\
\text { (5 min.) } \\
\text { Poste- } \\
\text { rior- } \\
\text { mente } \\
\text { en el lu- } \\
\text { gar de } \\
\text { tra- } \\
\text { bajo del } \\
\text { alumno. } \\
\text { (30 min.) }\end{array}$ & $\begin{array}{l}\text { EVALUACIÓN DE } \\
\text { LOS ESTILOS O } \\
\text { MODELOS DE } \\
\text { APRENDIZAJE }\end{array}$ & $\begin{array}{l}\text { El profesor inicia la clase salu- } \\
\text { dando a los alumnos y presenta un } \\
\text { cuestionario relacionado con los } \\
\text { modelos de aprendizaje del alum- } \\
\text { nado. Se entregará a cada uno de } \\
\text { los alumnos/as y lo completarán } \\
\text { en casa. } \\
\text { Ver Anexo II } \\
\text { Modelo para valorar los modelos } \\
\text { mentales de aprendizaje. } \\
\text { Versión digital: } \\
\underline{\text { http://guiaaprend.deusto.es/testo. }} \\
\underline{\text { asp }}\end{array}$ & $\begin{array}{l}\text { Por parte del } \\
\text { profesor en } \\
\text { el aula y del } \\
\text { alumnado en } \\
\text { su casa o lu- } \\
\text { gar de tra- } \\
\text { bajo como } \\
\text { tarea. }\end{array}$ \\
\hline $\begin{array}{l}\text { Cont. 2a } \\
\text { sesión } \\
\text { Inicio de } \\
\text { la clase } \\
(15 \mathrm{~m} .)\end{array}$ & $\begin{array}{l}\text { CORRECCIÓN } \\
\text { DE LOS MODE- } \\
\text { LOS MENTALES DE } \\
\text { APRENDIZAJE }\end{array}$ & $\begin{array}{l}\text { Se presentará una plantilla para } \\
\text { que cada alumno/a en función de } \\
\text { las respuestas dadas sobre los es- } \\
\text { quemas de modelos mentales de } \\
\text { aprendizaje las señale para su pos- } \\
\text { terior revisión por el profesor }\end{array}$ & \\
\hline $\begin{array}{l}\text { 3a sesión } \\
\text { Inicio de } \\
\text { la clase } \\
\text { (15min.) }\end{array}$ & $\begin{array}{l}\text { PRESENTACIÓN } \\
\text { AL ALUMNADO } \\
\text { DE LOS RESUL- } \\
\text { TADOS DE LOS } \\
\text { CUESTIONARIOS. }\end{array}$ & $\begin{array}{l}\text { Se presentarán los resultados de } \\
\text { los alumnos/as de forma anó- } \\
\text { nima indicando que modelos o es- } \\
\text { quemas de aprendizaje poseen } \\
\text { los mismos. Se contestarán aque- } \\
\text { llas dudas que surjan sobre los } \\
\text { distintos modelos de esquema de } \\
\text { aprendizaje. }\end{array}$ & $\begin{array}{l}\text { Revisión de } \\
\text { los ítems } \\
\text { por parte del } \\
\text { profesor. Ela- } \\
\text { boración de } \\
\text { un gráfico. }\end{array}$ \\
\hline
\end{tabular}

Jornadas de Formación e Innovación Docente del Profesorado | № 1 (2018) Esta obra se distribuye con la licencia Creative Commons Reconocimiento-NoComercial-SinObraDerivada Internacional (CC BY-NC-ND 4.0.) 


\begin{tabular}{|c|c|c|c|}
\hline $\begin{array}{l}\text { 4a sesión } \\
\text { Al ini- } \\
\text { cio del } \\
\text { tema } 4 \\
\text { (15-20 } \\
\text { aprox.) }\end{array}$ & $\begin{array}{l}\text { EVALUACIÓN INI- } \\
\text { CIAL DE CONTENI- } \\
\text { DOS DEL TEMA } 4 . \\
\text { ARTE ROMÁNICO }\end{array}$ & $\begin{array}{l}\text { Antes de dar comienzo el tema } \\
\text { mencionado, el profesor plantea } \\
\text { la realización de un torbellino de } \\
\text { ideas en la pizarra del aula. } \\
\text { Tras la participación de los alum- } \\
\text { nos, el profesor valora los resulta- } \\
\text { dos obtenidos. }\end{array}$ & $\begin{array}{l}\text { Inicio por } \\
\text { parte del } \\
\text { profesor para } \\
\text { motivar. Par- } \\
\text { ticipación } \\
\text { activa del } \\
\text { alumnado. } \\
\text { Valoración } \\
\text { del profesor. }\end{array}$ \\
\hline $\begin{array}{l}\text { 5a sesión } \\
\text { Al inicio } \\
\text { del tema } \\
5 \text { (15-20 } \\
\text { min.) }\end{array}$ & $\begin{array}{l}\text { EVALUACIÓN INI- } \\
\text { CIAL DE CONTENI- } \\
\text { DOS DEL TEMA } 5 . \\
\text { ARTE GÓTICO. }\end{array}$ & $\begin{array}{l}\text { Se plantea una actividad evalua- } \\
\text { tiva de conceptos, procedimientos } \\
\text { y actitudes con el uso de las TIC o } \\
\text { nuevas tecnologías, como la apli- } \\
\text { cación Kahoot. }\end{array}$ & $\begin{array}{l}\text { Presentación } \\
\text { de la activi- } \\
\text { dad y moti- } \\
\text { vación por } \\
\text { parte del } \\
\text { profesor. Par- } \\
\text { ticipación } \\
\text { activa del } \\
\text { alumnado. } \\
\text { Valoración y } \\
\text { comentario } \\
\text { deresultados. }\end{array}$ \\
\hline $\begin{array}{l}\text { 6a sesión } \\
\text { Una se- } \\
\text { mana } \\
\text { antes de } \\
\text { concluir } \\
\text { el tema } \\
\text { ante- } \\
\text { rior(15-20 } \\
\text { min.) }\end{array}$ & $\begin{array}{l}\text { EVALUACIÓN INI- } \\
\text { CIAL DE CON- } \\
\text { TENIDOS DEL } \\
\text { TEMA 6. ARTE DEL } \\
\text { RENACIMIENTO. }\end{array}$ & $\begin{array}{l}\text { Se plantea una actividad evalua- } \\
\text { tiva de conceptos, procedimientos } \\
\text { y actitudes presentando un cues- } \\
\text { tionario. Anexo II. }\end{array}$ & $\begin{array}{l}\text { Presentación } \\
\text { de la activi- } \\
\text { dad y moti- } \\
\text { vación por } \\
\text { parte del } \\
\text { profesor. Par- } \\
\text { ticipación } \\
\text { activa del } \\
\text { alumnado. } \\
\text { Valoración y } \\
\text { comentario } \\
\text { deresultados. }\end{array}$ \\
\hline $\begin{array}{l}\text { 7a- Ses. } \\
\text { desp. 1er. } \\
\text { Parc. }\end{array}$ & $\begin{array}{l}\text { EVALUACIÓN DEL } \\
\text { PROFESOR }\end{array}$ & $\begin{array}{l}\text { Se plantea una evaluación abierta } \\
\text { del modo aplaudo/ critico/ sugiero } \\
\text { a los alumnos. Añadir lo que desee } \\
\text { cada alumno. }\end{array}$ & $\begin{array}{l}\text { Presentación } \\
\text { de la tarea } \\
\text { por profesor. } \\
\text { Conclusiones } \\
\text { del profesor } \\
\text { en casa. }\end{array}$ \\
\hline
\end{tabular}

Jornadas de Formación e Innovación Docente del Profesorado | № 1 (2018) Esta obra se distribuye con la licencia Creative Commons Reconocimiento-NoComercial-SinObraDerivada Internacional (CC BY-NC-ND 4.0.) 


\begin{tabular}{|l|l|l|l|}
\hline Sesio- & VALORACIÓN DE & Se analizan los resultados del & Por parte del \\
nes tras & LOS RESULTADOS & $\begin{array}{l}\text { cuestionario. Se plantean conteni- } \\
\text { la reali- }\end{array}$ & DE LOS CONTENI- \\
dos, actividades y metodología a & \\
zac.de la & DOS DEL TEMA 6. & aplicar para exponer la materia. & \\
evaluac. & TOMA DE DECISIO- & & \\
inicial. & NES Y REORGA- & & \\
& NIZACIÓN DE LOS & & \\
& CONTENIDOS DEL & & \\
& TEMA, PREVIO A & & \\
& SU EXPOSICIÓN & & \\
& EN ELAULA. & & \\
\hline
\end{tabular}

\section{Aplicación del ciclo de mejora}

El ciclo de mejora se desarrolló conforme a la secuencia de actividades prevista. La evaluación inicial o de diagnóstico practicada siguiendo el cuestionario (Anexo I) sorprendió a los alumnos pues no sabían muy bien para que se aplicaba, si bien tras su explicación les permitió entender que la información recogida definiría en qué circunstancias habían trabajado con anterioridad la asignatura de Teoría e Historia del Arte. El análisis de los cuestionarios anónimos arrojó estos resultados.

El alumnado procede básicamente de Institutos de Enseñanza Secundaria (81,25\%), si bien el resto procede de Escuelas de Arte. En un porcentaje igualitario han recibido clases de Historia del Arte o de la asignatura Fundamentos de Arte indistintamente. Respecto a los últimos estilos artísticos estudiados hay un claro contraste pues algunos terminaron el tema dedicado al Barroco y otros llegaron hasta las corrientes artísticas del siglo XX. Respecto al sistema de evaluación un elevado porcentaje seguía el formato de la PAU (68,75\%), si bien otros hacían pruebas más teóricas. Respecto a las calificaciones del curso, un $75 \%$ obtuvo entre sobresaliente y notable, si bien tras hacer la selectividad un 87,5\%; de ellos un $58 \%$ obtuvo entre sobresaliente y notable. Todos cursaron la asignatura de Teoría e Historia del Arte I del primer trimestre, arrojando esta gráfica de calificaciones: (Fig. 3) 


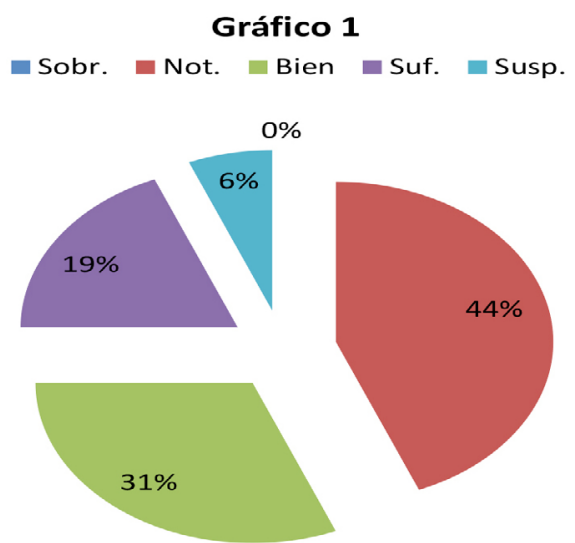

Fig. 3. Calificaciones de Teoría e Historia del Arte I

Estos resultados definen un grupo que conoce la materia de forma general, si bien hay algunos alumnos que necesitan mejorar la adquisición de competencias y contenidos de la asignatura de Historia del Arte. Para concluir, exponer que ninguno había cursado la asignatura en la que se desarrolla el ciclo de mejora.

Respecto a la aplicación del Cuestionario Honey original para conocer los modelos mentales de aprendizaje se deduce que la mayoría de los alumnos tienen un aprendizaje más reflexivo, otros más teóricos y menos activos. En cambio, en el caso de las alumnas se puede apuntar que son más reflexivas, siguiéndole las más pragmáticas y finalmente las teóricas. Esto nos hace pensar que las asignaturas teóricas como la que se está impartiendo no debe resultarles complicada.

Estos cuestionarios que se han mencionado se aplicaron al inicio de las primeras clases, si bien las distintas actividades que a continuación se exponen se hicieron al inicio de cada uno de las unidades didácticas o temas impartidos. La primera actividad se desarrollo al inicio del tema 4 y en la primera sesión planteando un torbellino de ideas sobre el tema del Arte Románico en la pizarra habitual del aula. Una alumna salió voluntaria a la misma y fue tomando nota de forma aleatoria cada uno de los términos o ideas que se fueron exponiendo por parte de todo el alumnado. Posteriormente, el profesor fue interrelacionando cada uno de los elementos o ideas que se 
expusieron. De ese modo se pudo apreciar los contenidos iniciales que conocían los alumnos, aunque algunos desconocían muchos de ellos. Para la evaluación inicial del tema 5 cuyos contenidos están relacionados con el Arte Gótico se hizo una actividad del tipo kahoot. No obstante, no se han recogido estos resultados por considerar más importante y más completa la evaluación inicial del tema 6 que a continuación se va a desarrollar. Al inicio de la unidad 6 dedicada al arte del Renacimiento se creyó oportuno realizar un cuestionario previo tratando conceptos de ese tema. (Anexo II) El cuestionario se pasó días antes de concluir la unidad anterior, tema 5, para de ese modo y tras su valoración elaborar un mapa conceptual donde se hiciera hincapié en aquellos contenidos que fuese más necesario tratar dadas las carencias o confusiones manifestadas en sus respuestas. (Fig. 3) Posteriormente, y al concluir el tema se volvió a pasar el cuestionario, esta vez sin los ítems del 8 al 10, para centrarnos únicamente en los contenidos. A continuación se presenta una escalera de aprendizaje donde se muestran los resultados obtenidos en las cuatro primeras preguntas. Corresponden a la serie 1 y de color azul las respuestas del cuestionario previo de evaluación inicial, a la serie 2 y de color rojo las respuestas de evaluación final tras la explicación del tema. (Fig. 4) Posteriormente, se presenta la escalera de aprendizaje de las tres últimas preguntas del cuestionario con idéntica leyenda de la anterior. (Fig. 5)

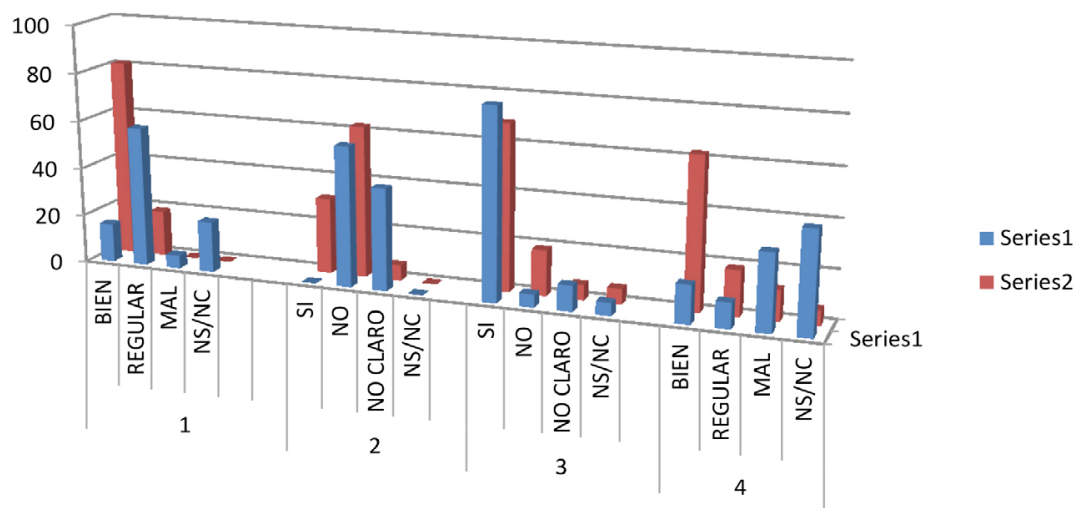

Fig. 4. Escaleras de aprendizaje. Preguntas n. 1 a 4

Jornadas de Formación e Innovación Docente del Profesorado | № 1 (2018) Esta obra se distribuye con la licencia Creative Commons 


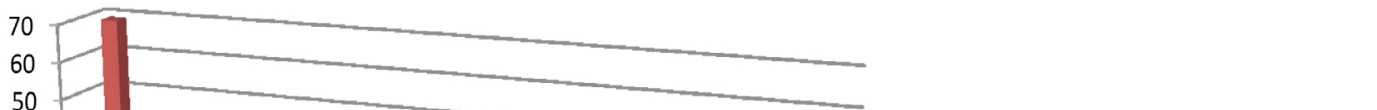

Fig. 5. Escaleras de aprendizaje. Preguntas n. 5 a 7

Una visión rápida de las mismas permite apreciar unos resultados muy positivos en las preguntas 1, 2, 4, 5, 6 y 7 . Únicamente la pregunta 3 relativa al Renacimiento como estilo artístico es la única en la que los resultados de la evaluación inicial es más positiva que la evaluación final. Por tanto, la lectura de esas escaleras de aprendizaje permite apreciar que el alumnado ha avanzado considerablemente en su conocimiento.

Respecto a la evaluación del profesor, por parte del alumnado, hay que decir que tras la realización del primer parcial y entrega de sus calificaciones, les sorprendió bastante que fuesen ellos quienes evaluasen al profesor, pues comentaban que nunca lo habían hecho de esa forma. Aseguraban que habían realizado alguna encuesta de satisfacción del profesor al final de la asignatura, pero nunca algo de este tipo aplaudo-critico-sugiero. Argumenté que fuesen sinceros, pues esa encuesta personal y anónima permitía mejorar y corregir la práctica docente antes de concluir la asignatura cuatrimestral. De su análisis se dedujo que los alumnos aplaudían: la conversación fluida y concisa con que exponía el profesor, la buena organización de los apuntes, la escucha y preocupación por el aprendizaje de los alumnos y la buena preparación de las clases. Por su parte, se valoraba positivamente que más de un 
$50 \%$ de los alumnos no criticaban nada y algún alumno exponía que en los últimos diez minutos de clase el docente desarrollaba la clase más rápida. Finalmente y como sugerencia se aportaba reducir la velocidad expositiva a la hora de concluir la clase, así como mantener la forma de explicación y metodología en un buen número de ellos.

\section{Evaluación del ciclo de mejora docente}

Tras la puesta en práctica de este ciclo de mejora se ve oportuno incluir algunas de las actividades o prácticas realizadas y que repercuten más directamente en la evaluación inicial o diagnóstica. De todas las actividades propuestas en la secuencia desarrollada con anterioridad, las siguientes se van a incluir en la práctica docente habitual:

- La evaluación inicial o diagnóstica de la asignatura se va a realizar todos los cursos académicos animando al alumnado a realizar el cuestionario (Anexo I) al inicio de la asignatura, pues ofrece información sobre cómo los alumnos se incorporan a la Universidad y por consiguiente, su incorporación a esta materia.

- La evaluación inicial antes de comenzar a desarrollar una unidad del temario donde se presenten cuestiones relacionadas con los contenidos propios del mismo. Este cuestionario con preguntas muy bien seleccionadas aportarán la información que se necesita para hacer una evaluación diagnóstica del tema. Tras la valoración por parte del docente se construirá o maquetará un mapa de contenidos conjugando el programa de la asignatura con las necesidades/carencias apreciadas en los discentes.

- La evaluación al profesor, por parte del alumnado, tras la realización del primer parcial. Siguiendo algún modelo de evaluación abierta del tipo aplaudo-critico-sugiero, pues en ese momento se pueden reorientar o cambiar algunas prácticas metodológicas para aplicarlas durante el resto del cuatrimestre. De 
ese modo, y tomando al alumnado como protagonista de su propio aprendizaje los resultados serán más positivos.

En definitiva, con esta comunicación se manifiesta y se pone en valor la importancia de la evaluación inicial o diagnóstica como una herramienta básica y poco practicada dentro del proceso enseñanza-aprendizaje en la Educación Superior. Gracias a ella, el docente es consciente de las competencias y contenidos que domina el discente puede redirigir todo el conjunto de la docencia y sus variables (contenidos, metodología y evaluación) y hacer al alumno protagonista de su aprendizaje.

\section{Bibliografía}

Alonso, C., Gallego, D., Honey, P. (1994). Los Estilos de Aprendizaje. Procedimientos de diagnóstico y mejora. Bilbao: Mensajero.

Bain, K. (2007). Lo que hacen los mejores profesores universitarios. (2a edición). Valencia: Universitat de València.

Finkel, D. (2008). Dar clase con la boca cerrada. Valencia: Universitat de València.

Giné, N. y Parcerisa, A. (2000). Evaluación en la educación secundaria. Elementos para la reflexión y recursos para la práctica. Barcelona: Graó

Ramos Suárez, M.A. (2016). "Como decíamos ayer..." Acerca de la participación del alumnado en la asignatura de Teoría e Historia del Arte. En Porlan Ariza, Navarro Medina (Coords.) III Jornadas de docencia universitaria. (pp. 256-264). Sevilla, Instituto de Ciencias de la Educación.

Ramos Suárez M.A. (2017) "Conocer, valorar y difundir lo nuestro" La visita cultural como actividad de ampliación y refuerzo al temario de Teoría e Historia del Arte. En Porlan Ariza, Navarro Medina (Coords.) IV Jornadas de Formación e Innovación Docente. (pp. 23-33). Sevilla: Instituto de Ciencias de la Educación.

Rivero, A.; Porlán, R. (2017). La evaluación en la enseñanza universitaria. En Enseñanza universitaria. Cómo mejorarla (pp. 73-91). Madrid: Morata. 
CUESTIONARIO PREVIO DE EVALUACIÓN INICIAL

HOMBRE/ MUJER:

EDAD: años.

RESPONDE A ESTAS PREGUNTAS:

1. Centro donde estudiaste antes de venir a la Facultad:

2. Antes de venir a la Facultad, ¿recibiste clases de Historia del Arte? Rodea lo que proceda.

$\mathrm{SI}$

NO

3. Si recibiste clases en esa materia, hasta qué estilo artístico trabajasteis:

4. ¿Cómo era el examen de Historia del Arte en el centro donde estudiaste?

5. ¿Qué calificación obtuviste en esa asignatura en el centro?

6. ¿Hiciste la prueba de Historia del Arte en la Selectividad? Rodea lo que proceda.

$\mathrm{SI}$

NO

7. ¿Qué calificación obtuviste en esa asignatura en Selectividad?

8. ¿Has recibido clases de Teoría e Historia del Arte I en la Facultad? Rodea lo que proceda.

$\mathrm{SI}$

NO

9. ¿Qué calificación obtuviste en esa asignatura en la Facultad?

10. La asignatura de Teoría e Historia del Arte ¿es tu primera o segunda matrícula?

Jornadas de Formación e Innovación Docente del Profesorado | № 1 (2018) Esta obra se distribuye con la licencia Creative Commons 
11. ¿Te has presentado alguna vez a las pruebas de Teoría e Historia del Arte II?

Rodea lo que proceda.

SI

NO

ANEXO II

CUESTIONARIO PREVIO DE EVALUACIÓN INICIAL DEL TEMA 6

HOMBRE/ MUJER:

EDAD: años.

RESPONDE A ESTAS PREGUNTAS:

1. Define el Renacimiento:

2. ¿Sabes si el Renacimiento y el Humanismo son el mismo concepto?

SI NO NO LO TENGO MUY CLARO

3. Con la definición que planteas, ¿sabes si el Renacimiento es un estilo artístico?

SI NO NO LO TENGO MUY

CLARO

4. ¿Qué fechas abarca el Renacimiento?

De a

5. ¿Sabes cómo vivían los artistas de esta época? (importancia reconocimiento,....)

Jornadas de Formación e Innovación Docente del Profesorado | № 1 (2018)

Esta obra se distribuye con la licencia Creative Commons

Reconocimiento-NoComercial-SinObraDerivada

4.0

Internacional (CC BY-NC-ND 4.0.) 
6. Escribe el nombre de tres arquitectos, tres escultores y tres pintores del Renacimiento.

7. Escribe el nombre de algún artista del Renacimiento y el nom bre de alguna obra suya:

8. ¿Dónde acudirías para saber más sobre este tema? Señala las que creas.

Apuntes de clase Wikipedia Internet Bibliografía recomendada

9. Hay algún aspecto concreto del tema que te llame más la atención y sobre el que desearía

conocer más:

10. A la hora de conocer aspectos sobre este tema, ¿qué preferirías? Que tu profesor expusiese el tema como siempre.

Elaborar un trabajo escrito de la materia y que el profesor te evalúe.

Elaborar un trabajo escrito de la materia y exponerlo en clase.

Jornadas de Formación e Innovación Docente del Profesorado | № 1 (2018)

Esta obra se distribuye con la licencia Creative Commons 